\title{
Ultrasound-Guided Radiofrequency Thermal Ablation of Uterine Fibroids: Medium-Term Follow-Up
}

\author{
Gianpaolo Carrafiello $\cdot$ Chiara Recaldini · \\ Federico Fontana $\cdot$ Fabio Ghezzi $\cdot$ Salvatore Cuffari $\cdot$ \\ Domenico Laganà $\cdot$ Carlo Fugazzola
}

Received: 12 February 2009/Accepted: 24 August 2009/Published online: 24 September 2009

(c) The Author(s) 2009. This article is published with open access at Springerlink.com

\begin{abstract}
Previous studies have shown that radiofrequency thermal ablation (RFA) of uterine fibroids through a percutaneous ultrasound (US)-guided procedure is an effective and safe minimally invasive treatment, with encouraging short-term results. The aim of this study was to assess the results in terms of volume reduction and clinical symptoms improvement in the midterm follow-up of fibroids with a diameter of up to $8 \mathrm{~cm}$. Eleven premenopausal females affected by symptomatic fibroids underwent percutaneous US-guided RFA. Symptom severity and reduction in volume were evaluated at 1, 3, 6, 9, and 12 months. The mean symptom score (SSS) before the procedure was 50.30 (range 31.8-67.30), and the average quality of life (QOL) score value was 62 (range 37.20-86.00). The mean basal diameter was $5.5 \mathrm{~cm}$ (range 4.4-8) and the mean volume was $101.5 \mathrm{~cm}^{3}$ (range $44.58-278 \mathrm{~cm}^{3}$ ). The mean follow-up was 9 months (range 3-12 months). The mean SSS value at the end of the follow-up was 13.38 (range 0-67.1) and the QOL 90.4 (range 43.8-100). At follow-up the mean diameter was $3.0 \mathrm{~cm}$ (range 1.20$4.5 \mathrm{~cm}$ ), and the mean volume was $18 \mathrm{~cm}^{3}$ (range 0.90 $\left.47.6 \mathrm{~cm}^{3}\right)$. In 10 of 11 patients we obtained total or partial
\end{abstract}

G. Carrafiello · C. Recaldini $(\bowtie) \cdot$ F. Fontana $\cdot$ D. Laganà .

C. Fugazzola

Department of Radiology, Ospedale di Circolo e Fondazione

Macchi, University of Insubria, Viale Borri 57, Varese 21100,

Italy

e-mail: chiarec@libero.it

F. Ghezzi

Department of Obstetrics and Gynecology, Ospedale F. Del

Ponte, University of Insubria, Varese, Italy

S. Cuffari

Service of Anesthesiology, Ospedale di Circolo e Fondazione

Macchi, University of Insubria, Varese, Italy regression of symptoms. In one case the clinical manifestations persisted and it was thus considered unsuccessful. In conclusion, US-guided percutaneous RFA is a safe and effective treatment even for fibroids up to $8 \mathrm{~cm}$.

Keywords Uterine fibroids - Radiofrequency ablation · Ultrasound · CEUS

\section{Introduction}

Uterine fibroids are the most common pelvic tumor of the female genital tract and tend to increase with age. The most frequent clinical symptoms are menorrhagia, pelvic pain, a feeling of pelvic fullness, and infertility [1]. In the last decades, social and cultural changes, along with technological improvements in medicine, have increased the need for women to retain their uterus, above all when symptomatic uterine fibroids are diagnosed at reproductive age and women wish to have children [2,3]. Hence, a large variety of less invasive alternatives to hysterectomy has been developed [4], such as myomectomy [5], uterine artery embolization (UAE) [6-8], cryomyolisis [9-11], high-intensity focused ultrasound (HIFU) [12-14], and recently radiofrequency thermal ablation (RFA) [15-19].

This study reports our experience on a group of patients whose uterine fibroids were treated using percutaneous ultrasound-guided RFA. Patients with fibroids up to $8 \mathrm{~cm}$ were included.

\section{Materials and Methods}

Between March 2006 and February 2008, 11 consecutive premenopausal women with symptomatic uterine fibroids 
not responsive to medical therapies (including progestin, oral contraceptives, and anti-inflammatory drugs) were recruited by the gynecologist at our hospital in this study to be submitted to RFA treatment.

Our inclusion criteria were women who had completed childbearing and absolutely declined hysterectomy. Exclusion criteria were the presence of more than three fibroids or of one fibroid $>8 \mathrm{~cm}$, a gynecological malignant pathology in the past 5 years, a pelvic inflammatory disease, abnormal coagulation tests, breastfeeding, and current pregnancy. All patients were counseled on the potential risks and benefits of the procedure before giving their own written consent. The Institutional Review Board granted authorization to collect data prospectively and approved the study.

All women were assessed regarding the severity of symptoms and the quality of life (QOL) by use of the Uterine Fibroids Symptom and Quality of Life questionnaire (UFS-QOL). This questionnaire consists of eight questions about the severity of the symptoms and 29 health-related quality of life questions. Two scores are calculated, one assesses the symptoms (SSS) and the other the QOL [20]. Raw scores were converted to a transformed score using the following formula: transformed scor$\mathrm{e}=($ raw score -8$) / 32 \times 100$. The transformed score varied from 0 to 100 , with 100 being the most severely symptomatic. Such clinical evaluation was also repeated 3 months after treatment, at the same time as the instrumental evaluation.

The pretreatment evaluation was performed with transvaginal and suprapubic ultrasound (US) to determine the number, dimensions, and location of the myomas. The uterine fibroids volume was calculated by the following formula: volume $=0.5233 \times \mathrm{D} 1 \times \mathrm{D} 2 \times \mathrm{D} 3$, where $\mathrm{D} 1$ is the longitudinal dimension, D2 is the anterior-posterior dimension, and D3 is the transverse one [21].

Procedures were performed at the day hospital and patients were under moderate sedation (intravenous administration of $1-3 \mathrm{mg}$ midazolam, $1-3 \mathrm{mg}$ fentanyl, and 50-120 mg propofol) in the presence of the anesthetist. All patients received an antibiotic prophylaxis according to an "ultra-short-term antibiotic prophylaxis" scheme with a preprocedural intravenous injection of $1 \mathrm{~g}$ of cefazolin to obtain a hematic peak concentration of the medicine at the moment of necrosis.

We used the Le Veen coaxial needle electrode, 3.5 or $4 \mathrm{~cm}$ (Boston Scientific, Natick, MA, USA), with 10-14 hooks at the extremity, which were opened during the procedure. In the two patients with fibroids $>6 \mathrm{~cm}$, two needle deployments were performed to obtain a volume of necrosis comparable to the volume of fibroids. The needle electrode was connected to a generator (RF 3000 Generator; Boston Scientific) that operates at a maximum power of $250 \mathrm{~W}$ and at temperatures ranging from 15 to $125^{\circ} \mathrm{C}$; the generator displays the tissue impedance characteristics as well as the ablation power and time. The selected temperature to reach within the tissue was $85^{\circ} \mathrm{C}$ and the generator automatically adjusted the power to maintain that temperature $(150 \mathrm{~W})$.

Real-time suprapubic US was used to perform the procedure transpelvically. To avoid hemorrhagic complications, cauterization of the needle track was obtained at the end of the procedure by setting the generator at $10 \mathrm{~W}$ of power while removing the needle.

We evaluated the presence of both intra- and postprocedural minor and major complications in all patients. Minor complications were defined as temporary and selflimiting symptoms requiring no therapy or normal therapy without any clinical sequelae. Major complications were defined as those requiring further interventions and/or hospitalization.

Technical success was assessed 1 day after the procedure by suprapubic US with the administration of a $2.5-\mathrm{ml}$ bolus of second-generation contrast medium (Sonovue; Bracco, Milan, Italy), followed by $10 \mathrm{ml}$ of physiological solution. Contrast-enhanced ultrasound (CEUS) exams were performed with Technos MPX (Esaote Biomedica, Genoa, Italy) and IU 22 (Philips; Best, The Netherlands) ultrasound equipment. Instrumental evaluation of results at 1, 3, 6, 9, and 12 months after treatment was performed by CEUS and the following criteria were assessed: the presence of a necrotic area-defined as a hyphoechoic area without contrast medium enhancement-and diameter reduction.

Statistical analysis was performed with GraphPad Prism version 3.00 for Windows (GraphPad Software, San Diego, CA, USA). Statistical significance was set at $P<0.05$.

The aims of the study were, first, to assess the feasibility of RFA of uterine fibroids up to $8 \mathrm{~cm}$ and, second, to assess SSS and QOL improvements and volume shrinkage at midterm follow-up.

\section{Results}

Results are summarized in Table 1. Eleven premenopausal women (mean age 40.4; range 27-51), with a single uterine fibroid in 10 cases and two fibroids in 1 case (of which only the largest one was treated), underwent RFA. In one case the fibroid had an anterior submucosal position, in one case a posterior intramural one, in four cases an anterior intramural position, in four cases a fundic one, and in one case it was located in the left parietal. Patients showed symptoms such as pelvic pain (10/11), menorrhagia (8/11), and a feeling of pelvic fullness (1/11) and they were not responsive to medical therapies.

The mean SSS value before the procedure was 50.30 (range 31.8-67.30), and the mean QOL score value was 62 
Table 1 Age, mean diameter and volume reduction, and changes in SSS and QOL in 11 patients

\begin{tabular}{|c|c|c|c|c|c|c|c|}
\hline \multirow{2}{*}{$\begin{array}{l}\text { Patient ID } \\
\text { and age }\end{array}$} & \multirow[t]{2}{*}{ Parameter } & \multicolumn{6}{|c|}{ Time (month) } \\
\hline & & 0 & 1 & 3 & 6 & 9 & 12 \\
\hline \multirow[t]{4}{*}{ (A) 42} & Diameter $(\mathrm{cm})$ & 5 & 4.20 & 3.10 & 2.20 & 2.00 & 2.00 \\
\hline & Volume $\left(\mathrm{cm}^{3}\right)$ & 65.42 & 38.77 & 15.59 & 5.57 & 4.19 & 4.19 \\
\hline & SSS & 44.20 & - & 20.20 & 6.10 & 2.00 & 00 \\
\hline & QOL & 66.20 & - & 84.30 & 98.00 & 100.00 & 100.00 \\
\hline \multirow[t]{4}{*}{ (B) 42} & Diameter $(\mathrm{cm})$ & 4.90 & 3.80 & 3.70 & 3.10 & 1.30 & 1.20 \\
\hline & Volume $\left(\mathrm{cm}^{3}\right)$ & 61.57 & 28.72 & 26.51 & 15.59 & 1.15 & 0.90 \\
\hline & SSS & 67.30 & - & 38.00 & 8.20 & 00 & 00 \\
\hline & QOL & 76.30 & - & 90.20 & 95.30 & 99.00 & 100.00 \\
\hline \multirow[t]{4}{*}{ (C) 39} & Diameter $(\mathrm{cm})$ & 4.40 & 3.70 & 3.30 & 2.00 & 1.90 & 1.90 \\
\hline & Volume $\left(\mathrm{cm}^{3}\right)$ & 44.58 & 26.51 & 18.81 & 4.19 & 3.59 & 3.59 \\
\hline & SSS & 52.40 & - & 35.30 & 00 & 00 & 00 \\
\hline & QOL & 53.90 & - & 77.00 & 99.10 & 99.00 & 99.00 \\
\hline \multirow[t]{4}{*}{ (D) 40} & Diameter $(\mathrm{cm})$ & 5.2 & 4.20 & 3.60 & 3.10 & 3.10 & - \\
\hline & Volume $\left(\mathrm{cm}^{3}\right)$ & 73.58 & 38.77 & 24.42 & 15.59 & 15.59 & - \\
\hline & SSS & 31.80 & - & 10.00 & 3.20 & 3.00 & - \\
\hline & QOL & 37.20 & - & 65.30 & 89.10 & 92.00 & - \\
\hline \multirow[t]{4}{*}{ (E) 42} & Diameter $(\mathrm{cm})$ & 4.5 & 3.90 & 3.20 & 2.80 & 2.60 & - \\
\hline & Volume $\left(\mathrm{cm}^{3}\right)$ & 47.69 & 31.04 & 17.15 & 11.49 & 9.20 & - \\
\hline & SSS & 40.30 & - & 8.00 & 2.00 & 1.90 & - \\
\hline & QOL & 86.00 & - & 90.00 & 100.00 & 100.00 & \\
\hline \multirow[t]{4}{*}{ (F) 42} & Diameter $(\mathrm{cm})$ & 4.8 & 4.1 & 3.2 & - & - & - \\
\hline & Volume $\left(\mathrm{cm}^{3}\right)$ & 58.58 & 31.04 & 18.81 & - & - & - \\
\hline & SSS & 47.2 & - & 26.00 & - & - & - \\
\hline & QOL & 63.92 & - & 86.30 & - & - & - \\
\hline \multirow[t]{4}{*}{ (G) 51} & Diameter $(\mathrm{cm})$ & 5.3 & 5.3 & 5.3 & - & 3 & - \\
\hline & Volume $\left(\mathrm{cm}^{3}\right)$ & 78 & 78 & 78 & - & 14 & - \\
\hline & SSS & 50.6 & 35.20 & 23 & - & 23 & - \\
\hline & QOL & 70.1 & 78 & 84.30 & - & 84.30 & - \\
\hline \multirow[t]{4}{*}{ (H) 45} & Diameter $(\mathrm{cm})$ & 8.1 & 4.8 & 4.5 & 4.5 & - & - \\
\hline & Volume $\left(\mathrm{cm}^{3}\right)$ & 278 & 57 & 47 & 47 & - & - \\
\hline & SSS & 47 & 0 & 0 & 0 & - & - \\
\hline & QOL & 55.1 & 100 & 100 & 100 & - & - \\
\hline \multirow[t]{4}{*}{ (I) 27} & Diameter $(\mathrm{cm})$ & 6 & - & - & 3.9 & 3.9 & 3.5 \\
\hline & Volume $\left(\mathrm{cm}^{3}\right)$ & 113 & - & - & 31 & 31 & 22 \\
\hline & SSS & 40.5 & - & - & 18 & 18 & 18 \\
\hline & QOL & 76.3 & - & - & 89.20 & 89.20 & 89.20 \\
\hline \multirow[t]{4}{*}{ (L) 41} & Diameter $(\mathrm{cm})$ & 7.06 & 5 & 5 & 5 & 3.03 & 3.03 \\
\hline & Volume $\left(\mathrm{cm}^{3}\right)$ & 184 & 65 & 65 & 65 & 14.60 & 14.60 \\
\hline & SSS & 65 & 17 & 17 & 17 & 0 & 0 \\
\hline & QOL & 53 & 87.8 & 87.8 & 87.8 & 100 & 100 \\
\hline \multirow[t]{4}{*}{ (M) 34} & Diameter $(\mathrm{cm})$ & 6 & 4.5 & 4.5 & Hysterectomy & & \\
\hline & Volume $\left(\mathrm{cm}^{3}\right)$ & 113 & 47.6 & 47.6 & & & \\
\hline & SSS & 67.1 & 67.1 & 67.1 & & & \\
\hline & QOL & 43.8 & 43.8 & 43.8 & & & \\
\hline
\end{tabular}

(range 37.20-86.00). The mean basal diameter of the treated fibroids was $5.5 \mathrm{~cm}$ (range $4.4-8 \mathrm{~cm}$ ) and the mean volume was $101.5 \mathrm{~cm}^{3}$ (range $44.58-278 \mathrm{~cm}^{3}$ ).
Needle insertion inside the fibroid was carried out without any problems and enabled the maximum opening of the hooks (as visualized by US with two orthogonal 
incidents). The operative time ranged from 15 to $25 \mathrm{~min}$ (average $20 \mathrm{~min}$ ). No intra- or postoperative complications occurred. In two cases the patients complained of medium abdominal pain, which was treated with a NSAID: in one case we observed some fluid in the pelvic pouch on the postprocedural suprapubic US, which disappeared at the following US checkup. Patients were admitted to the gynecologic day hospital in the morning and discharged home in the evening.

Technical success was obtained in all patients $(100 \%)$ : CEUS studies revealed complete ablation of the fibroids, showing a hypoechoic vascular area due to necrosis. The mean US follow-up was 9 months (range 3-12 months); at the last checkup the mean SSS value was 13.38 (range 0-67.1) and the mean QOL was 90.4 (range 43.8-100); the mean diameter was $3.0 \mathrm{~cm}$ (range $1.20-4.5 \mathrm{~cm}$ ) and the mean volume $18 \mathrm{~cm}^{3}$ (range $0.90-47.6 \mathrm{~cm}^{3}$ ). The mean QOL value recorded was 77.4 at 1 month (4 cases), 80.9 at 3 months (10 cases), 95 at 6 and 9 months ( 8 cases), and 97 at 12 months (5 cases) (Fig. 1). At the last checkup 6 of 11 patients $(54 \%)$ were asymptomatic, while for 4 patients (36\%) the symptoms had clearly decreased. In 10 of 11 cases $(91 \%)$ the SSS and QOL values improved. In nine patients $(81 \%)$ the fibroid volume reduction rate was always $>65 \%$ (min 65\%-max 98\%) at 6-, 9-, and 12-month followup. In two patients, for whom we only had the 3-month follow-up, the volume reduction was 58 and $68 \%$, respectively. The mean volume reduction was $46.9 \%$ at 1 -month checkup (10 cases), $53 \%$ at 3 months (10 cases), $79 \%$ at 6 months ( 8 cases), $86 \%$ at 9 months ( 8 cases), and $91 \%$ at 12-month follow-up (5 cases) (Fig. 2). In one case only (9\%; patient M, Table 1), even though the fibroid volume decreased, neither the pain nor the menorrhagia showed any sign of improvement, and the QOL and SSS values remained unchanged. Hence the patient underwent hysterectomy. During hysterectomy no adhesions were found and histology showed two necrotic adjacent nodules at the endometrial surface due to the previous RFA procedure.

We did not observe any revascularization phenomena in the treated fibroids, nor did we need to repeat a RFA treatment.

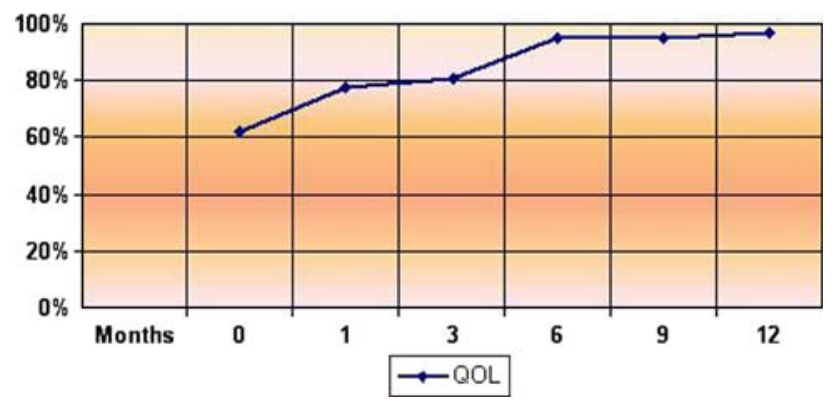

Fig. 1 Changes in QOL during follow-up

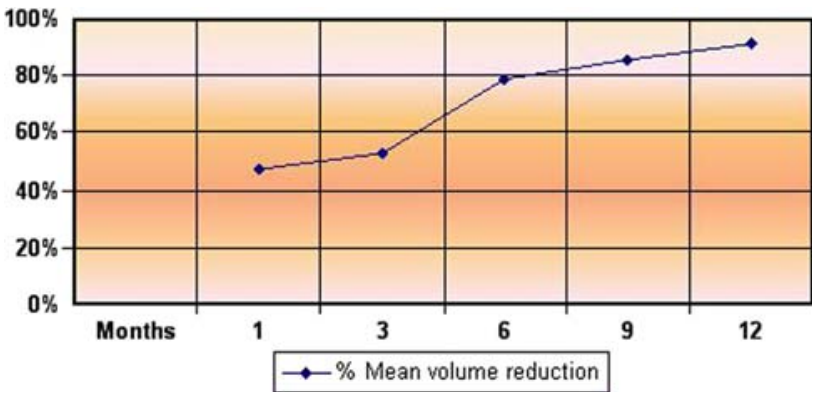

Fig. 2 Changes in volume during follow-up

\section{Discussion}

In a literature review (Table 2), we observed that 70 women (mean age 42.8) underwent RFA of uterine fibroids, $29(42 \%)$ by laparoscopy and $41(58 \%)$ percutaneously [15-19]. The RITA Medical System needle electrode was the most used. These studies have taken into account no more than three tumors at a time or tumors $<6 \mathrm{~cm}$ because RFA needles can produce at least a 5- to $6-\mathrm{cm}$ necrotic area in a single deployment.

In 2005 Bergamini et al. [18] conducted the first clinical experiment in which 18 patients with symptomatic uterine fibroids underwent an RFA treatment by laparoscopy. The study highlighted the ablative efficacy (for nine patients the volume decreased by $85 \%$, the SSS decreased, and the QOL improved) and the absence of immediate or late complications. Subsequent studies by Ghezzi et al. [15] and Milic et al. [17] showed similar results as far as volume reduction and symptoms improvements are concerned: in the study by Ghezzi et al. [15], the mean follow-up was 24 months (range 12-36 months), with a 70\% volume reduction of treated fibroids at 6 months and stable results at the 3-year follow-up. Kim et al. [19] treated 35 patients with percutaneous RFA after having performed UAE to improve its clinical efficacy. Six months after treatment, the mean volume reduction was $56 \%$, and at the same time symptoms had improved. In one case only the procedure was not successful [15]; in two cases $[15,17]$ the patients underwent hysterectomy after RFA treatment because of pain not responsive at 5 and 12 months. Early or late major complications did not occur in any series.

Our personal series confirms the results published in the literature, showing that this treatment can be feasible and effective in reducing volume and improving symptoms. For 9 of 11 patients we obtained a shrinkage rate $>65 \%$ at the 6-month follow-up. The following control at 12 months confirmed stability and revealed further volume reduction. Only one case was unsuccessful, because of persisting pain, hence the patient underwent hysterectomy. In our experience, considering the benign pathology 
Table 2 Literature review

\begin{tabular}{|c|c|c|c|c|c|c|}
\hline Reference & $N$ & Technique & $\begin{array}{l}\text { Follow-up } \\
\text { (months) }\end{array}$ & Symptom & Complication(s) & Volume reduction \\
\hline $\begin{array}{l}\text { Bergamini et al. } \\
2005 \text { [18] }\end{array}$ & 18 & Laparoscopy & 10 & $\begin{array}{l}\text { SSS 4.7, QOL 100, } \\
\text { at } 6 \text { months }\end{array}$ & 2 abdominal pain & $\begin{array}{l}83 \% \text { at } 9 \text { and } \\
12 \text { months }\end{array}$ \\
\hline $\begin{array}{l}\text { Ghezzi et al. } \\
2007 \text { [15] }\end{array}$ & $18+7$ & Laparoscopy & 24 & $\begin{array}{l}\text { SSS } 4.7 \text {, QOL 99.1, } \\
\text { at } 6 \text { months }\end{array}$ & 1 hysterectomy at 1 year & $\begin{array}{l}68.8 \% \text { at } 6 \text { months, } \\
77.9 \% \text { at } 1 \text { year, } \\
83.9 \% \text { at } 3 \text { years }\end{array}$ \\
\hline Milic et al. [17] & 4 & Laparoscopy & 3 & $\begin{array}{l}\text { Symptom improvement, } \\
2 / 4\end{array}$ & $\begin{array}{l}1 \text { technical failure, } \\
1 \text { hysterectomy } \\
\text { at } 5 \text { months }\end{array}$ & \\
\hline Kim et al. [19] & 35 & $\begin{array}{l}\text { Embolization }+ \\
\text { percutaneous RFA }\end{array}$ & 6 & $\begin{array}{l}\text { QOL } 17.4 \\
\text { at } 6 \text { months }\end{array}$ & $\begin{array}{l}1 \text { urinary tract infection, } \\
3 \text { post-embolization } \\
\text { syndrome }\end{array}$ & $56 \%$ at 6 months \\
\hline $\begin{array}{l}\text { Recaldini et al. } \\
2007[16]\end{array}$ & 6 & Percutaneous RFA & 7 & SSS 4.2, QOL 97.5 & & $82 \%$ \\
\hline
\end{tabular}

Note: $N$ number of patients

and the stability of the results at 6 months, we used a maximum instrumental 12-month follow-up. Moreover, Ghezzi et al. [14] over a follow-up of 3 years, did not register any major modifications in volume reduction or symptom improvement.

In our series, in the two patients with a fibroid larger than $6 \mathrm{~cm}$ we obtained a considerable volume reduction
(90\%), which proved to be stable at the following checkup 12 months later. In the patient affected by an 8-cm fibroid, the 6-month follow-up showed a shrinkage of $84 \%$. However, it has not been possible to assess the stability over time, as no subsequent checkups were available. In both cases we performed two needle positionings without any peri- or postprocedural complications (see Fig. 3).
Fig. 3 A 41-year-old woman affected by a 7 -cm symptomatic uterine fibroid. A B-mode US shows a hypoechoic mass in the uterus. B CEUS confirms rich vascularization inside the mass. C B-mode US 6 months after percutaneous RFA: the treated fibroid appears

nonhomogeneous and reduced in size. D CEUS confirmed a huge area of necrosis with a peripheral rim of enhancement in a normal uterus without any residual disease
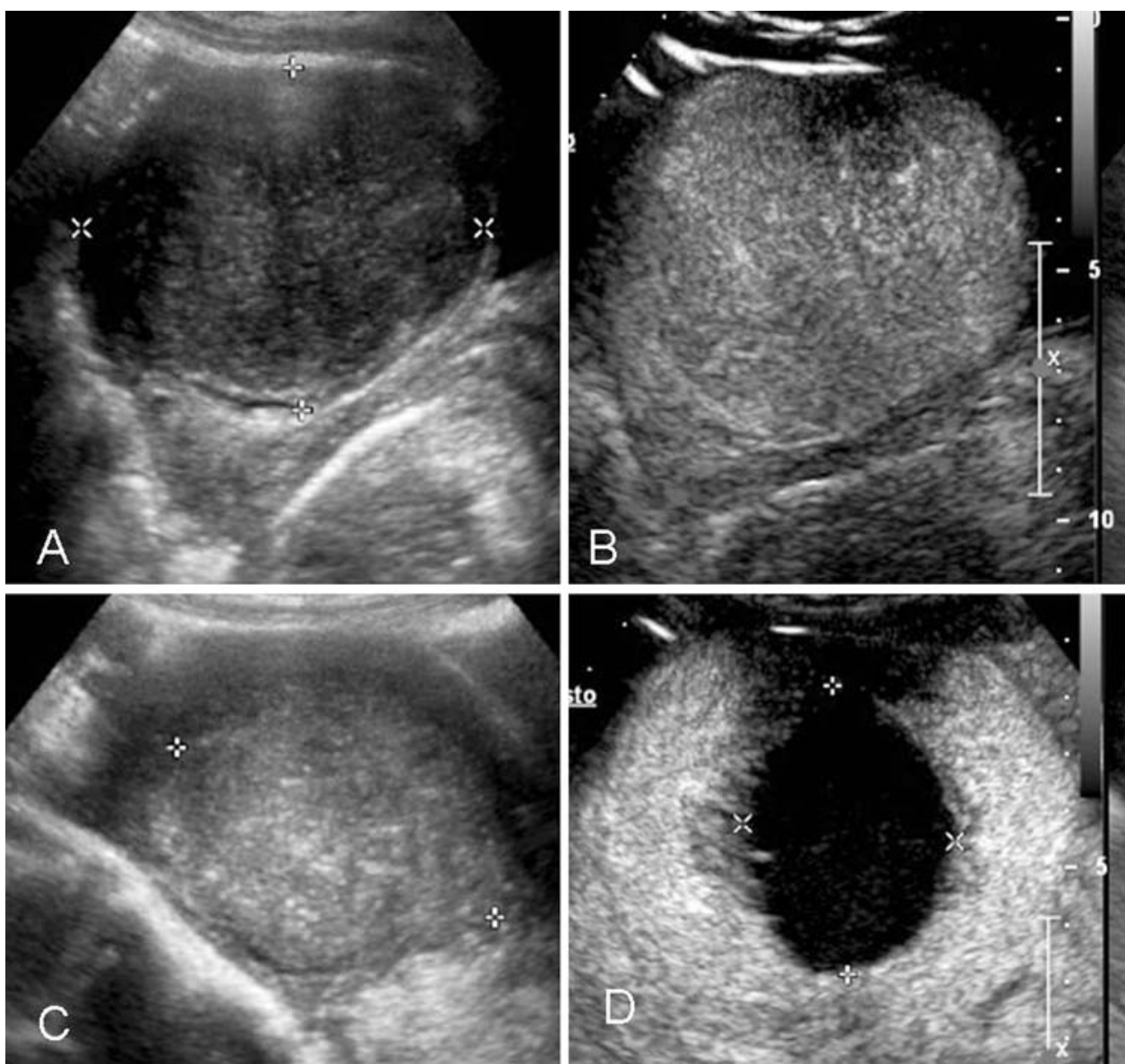
Our results, compared with those of Kim et al. [19], introduce the possibility of treating fibroids up to $8 \mathrm{~cm}$ without performing UAE before RFA. However, more extensive studies, with both a larger number of patients and a longer follow-up, should be conducted to prove the results' stability over time.

Both the transpelvic procedure and the needle insertion at depth were performed using suprapubic US guidance, which lowered the risk of lesion to nearby organs. CEUS is able to show the presence of vital tissue during the followup in order to recognize failures or recurrences early on [22]. CEUS exams are fast and reliable at showing a perilesional peripheral rim at 1 day, due to reactive hyperemy, only partially recognizable at the 3-month checkup. At our hospital we did not perform routine preprocedural imaging or follow-up with MR as elsewhere [23-25], because MR is not readily available at our institution for this purpose.

RFA represents a safe procedure with a low risk of complications. In our study we did not encounter any major complications, including bleeding, which can be successfully prevented by the use of a track ablation technique to coagulate perimyoma vessels along the access path. It is not possible to assess the risk of adhesions linked to thermal lesions of the bowels, as our follow-up was so short. Only with a longer follow-up would we be able to compare such risk with that linked to laparoscopic thermal ablation and traditional surgical techniques. From a technical point of view injection of saline solution among the bowel loops could be useful in some cases.

The larger cohort and longer follow-up of our series compared to previous published papers confirm the results proving the treatment's feasibility and its efficacy in terms of volume reduction and clinical symptom improvement. It also introduces the possibility of treating larger fibroids and it highlights the technical feasibility of multiple needle electrode placement without further peri- or postprocedural complications. Nevertheless, these results are preliminary, as the number of patients was restricted and the actual follow-up time limited.

Open Access This article is distributed under the terms of the Creative Commons Attribution Noncommercial License which permits any noncommercial use, distribution, and reproduction in any medium, provided the original author(s) and source are credited.

\section{References}

1. Ankem K (2007) Information-seeking behaviour of women in their path to an innovative alternate treatment for symptomatic uterine fibroids. JMLA 95(2):164-172
2. Apgar BS, Kaufman AH, George-Nwogu U, Kittendorf A (2007) Treatment of menorrhagia. Am Fam Phys 75(12):1820

3. Evans P (2007) Uterine fibroid tumors: diagnosis and treatment. Am Fam Phys 75(10):1452-1458

4. Siskin G (2006) New treatments for uterine fibroids. Tech Vasc Interv Radiol 9(1):12-18R

5. Mais V, Ajossa S, Guerriero S, Mascia M, Solla E, Melis GB (1996) Laparoscopic versus abdominal myomectomy: a prospective, randomized trial to evaluate benefits in early outcome. Am J Obstet Gynecol 174:654-658

6. Lumsden MA (2002) Embolization versus myomectomy versus hysterectomy. Hum Reprod 17:253-259

7. Worthington-Kirsch R, Spies JB, Myers ER et al (2005) The fibroid registry for outcomes data (fibroid) for uterine embolization. Obstet Gynecol 106:52-59

8. Bratby MJ, Hussain FF, Walker WJ (2008) Outcomes after unilateral uterine artery embolization: a retrospective review. Cardiovasc Interv Radiol 31:254-259

9. Cowan BD, Sewell PE, Howard JC et al (2002) Interventional magnetic resonance imaging cryoablation of uterine fibroids tumors: preliminary observation. Am J Obstet Gynecol 186: $1183-1187$

10. Zupi E, Sbracia M, Marconi D, Munro MG (2006) Myolysis of uterine fibroids: Is there a role? Clin Obstet Gynecol 49(4): 821-833

11. Zupi E, Marconi D, Sbracia M et al (2005) Directed laparoscopic cryomyolysis for symptomatic leiomyomata: 1-year follow-up. J Minim Invas Gynecol 12:343-346

12. Chapman A, Harr G (2007) Thermal ablation of uterine fibroids using MR-guided focused ultrasound-a truly non-invasive treatment modality. Eur Radiol 17:2505-2511

13. Fennessy FM, Tempany CM (2006) A review of magnetic resonance imaging-guided focused ultrasound surgery of uterine fibroids. Top Magn Reson Imaging 17(3):173-179

14. Tempany CM, Stuart EA, McDannold N et al (2003) MR imaging-guided focused ultrasound surgery of uterine leiomyomas: a feasibility study. Radiology 226:897-905

15. Ghezzi F, Cromi A, Bergamini V et al (2007) Midterm outcome of radiofrequency thermal ablation for symptomatic uterine myomas. Surg Endosc 21(11):2081-2085

16. Recaldini C, Carrafiello G, Laganà D et al (2007) Percutaneous sonographically ablation of medium-sized fibroids: feasibility study. AJR Am J Roentgenol 189(6):1303-1306

17. Milic A, Asch MR, Hawrjljshjn PA et al (2006) Laparoscopic ultrasound-guided radiofrequency ablation of uterine fibroids. Cardiovasc Interv Radiol 29(4):694-698

18. Bergamini V, Ghezzi F, Cromi A et al (2005) Laparoscopic radiofrequency thermal ablation: a new approach to symptomatic uterine myomas. Am J Obstet Gynecol 192(3):768-773

19. Kim HS, Tsai J, Jacobs MA, Kamel IR (2007) Percutaneous image-guided radiofrequency thermal ablation for large symptomatic uterine leiomyomata after uterine artery embolization: a feasibility and safety study. J Vasc Interv Radiol 18:41-48

20. Spies JB, Coyne K, Guaou N et al (2002) The UFS-QOL, a new disease specific symptom and health-related quality of life questionnaire for leiomyomata. Am J Coll Obstet Gynecol 99(2):290-300

21. Orsini L, Salardi S, Pilu G, Bovicelli L, Cacciari E (1984) Pelvic organs in premenarcheal girls: real-time ultrasonography. Radiology 153:113-116

22. Dorenberg EJ, Jakobsen JA, Braband K, Hafsahl G, Smith HJ (2007) The feasibility of contrast-enhanced ultrasound during 
artery embolization: a pilot study. Cardiovasc Interv Radiol 30:882-887

23. Volkers NA, Hehenkamp WJ, Spijkerboer AM et al (2008) MR reproducibility in the assessment of uterine fibroids for patients scheduled for uterine artery embolization. Cardiovasc Interv Radiol 31:260-268

24. Walker WJ, Brabty MJ (2007) Magnetic resonance imaging (MRI) analysis of fibroid location in women achieving pregnancy after uterine artery embolization. Cardiovasc Interv Radiol 30:876-881

25. Pelage JP, Guaou-Guaou N, Jha RC, Ascher SM, Spies JB (2004) Uterine fibroids tumors: long-term MR imaging outcome after embolization. Radiology 230:803-809 